\title{
Mapeamento estrutural de analogias enunciadas em uma aula sobre cinética química
}

\author{
Structural mapping of analogies \\ used in a class about chemical kinetics
}

Alexandre da Silva Ferry ${ }^{1}$. Helder de Figueirêdo e Paula ${ }^{2}$

\begin{abstract}
Resumo: Este artigo recorreu à Teoria do Mapeamento Estrutural das comparações proposta por Dedre Gentner para responder a duas questões de pesquisa: (i) quais características nos permitem identificar uma comparação estabelecida por um professor como sendo uma analogia?; (ii) que articulação é estabelecida entre comparações distintas que tratam de um mesmo tema, conceito ou modelo científico? Para responder a essas e a outras questões, observamos e registramos em áudio e vídeo uma sequência de ensino. Para a elaboração deste trabalho, selecionamos, transcrevemos e mapeamos estruturalmente quatro comparações produzidas por professor em uma mesma aula. A análise evidenciou a complexidade e a sofisticação de algumas analogias construídas pelo professor e a forma como elas são preparadas a partir de comparações menos complexas. Por fim, o trabalho também mostra o potencial do mapeamento estrutural de comparações como ferramenta para a análise do uso desse recurso discursivo como mediação para o ensino de Química.
\end{abstract}

Palavras-chave: Ensino de química. Analogia. Mapeamento estrutural de comparações. Ensino de ciências.

\begin{abstract}
This paper uses the Dedre Gentner's Structure-Mapping Theory of Comparisons to answer two questions: (i) what characteristics allow us to identify a comparison as being an analogy? (ii) what coordination is established between different comparisons which deals with the same topic, concept or scientific model? To answer these and other questions, we observe a sequence of teaching. We also recorded it on video and audio. To write this paper we chose, transcribed and structurally mapped four comparisons established by this teacher during a same class. Our analysis shows the complexity and the sophistication of some analogies. In addition, it shows how they are prepared from less complex comparisons. Finally, our work shows the power of the structural mapping of comparisons to help us understand how these mediational means are used to teach Chemistry.
\end{abstract}

Keywords: Chemistry teaching. Analogy. Structure-mapping of comparisons. Science teaching.

\footnotetext{
${ }^{1}$ Centro Federal de Educação Tecnológica de Minas Gerais (CEFET-MG), Departamento de Química, Belo Horizonte, MG, Brasil. E-mail: <asferry@deii.cefetmg.br>.

${ }^{2}$ Colégio Técnico da Universidade Federal de Minas Gerais (COLTEC), Setor de Física, Belo Horizonte, MG, Brasil.
} 


\section{Introdução}

Historicamente, o estudo sobre o papel das comparações no ensino de Ciências foi realizado, principalmente, em pesquisas sobre analogias. Tais pesquisas têm sido orientadas a partir de inúmeros enfoques e ainda há poucos trabalhos que investigaram como os professores constroem ou utilizam analogias em sala de aula de Ciências. Alguns trabalhos com essa perspectiva foram realizados na década de 1990 (DAGHER, 1995; THIELE; TREAGUST, 1994; TREAGUST et al., 1992). Na década seguinte, no Brasil, encontramos os trabalhos de Ferraz e Terrazzan (2001, 2002 e 2003), e de Bozelli e Nardi (2006, 2012).

Os três trabalhos de Ferraz e Terrazzan mencionados acima têm propósitos complementares, pois foram produzidos a partir de uma mesma pesquisa de mestrado. Nessa pesquisa, os autores observaram a prática pedagógica de 6 professoras de Biologia para "[...] investigar as formas de utilização de analogias e/ou metáforas por professores do Ensino Médio" (FERRAZ; TERRAZZAN, 2001, p. 4). No trabalho publicado em 2002, os autores identificaram se as analogias usadas espontaneamente pelas professoras procediam dos livros didáticos, do repertório dessas professoras, etc. No artigo de 2003, os autores contrastaram o uso de analogias pelas professoras com os passos propostos pela metodologia de ensino conhecida como teaching with analogies. (HARRISON; TREAGUST, 1994). No trabalho de Bozelli e Nardi (2006), os autores interpretaram o discurso de um professor de Física, a fim de identificar as situações que criavam a necessidade de produzir e utilizar analogias. Nessa mesma linha, Bozelli e Nardi (2012) analisaram a elaboração, utilização e exploração de analogias durante os processos de interação discursiva em sala de aula.

Em todos os trabalhos de Ferraz e Terrazzan já citados, os autores assumem as analogias como recursos didáticos disponíveis no processo de construção dos conceitos científicos e como ferramentas de uso frequente em sala de aula. Esse entendimento sobre o papel das analogias parte do pressuposto de que o raciocínio analógico contribui para que os estudantes compreendam o conhecimento científico, na medida em que os auxilia a usar conhecimentos de domínios que lhes são mais familiares (domínios base) no tratamento de domínios menos familiares (domínios alvo).

Em Bozelli e Nardi (2006) a analogia, assim como a metáfora, é considerada uma figura de linguagem usada como recurso mediador dos processos de ensino e aprendizagem. Os autores consideram as analogias como fundamentais para o tratamento de temas complexos, visto que estas permitem relacionar atributos e relações constitutivas dos domínios familiares e não familiares.

Em nenhum dos cinco trabalhos mencionados encontramos critérios para distinguir as analogias de outros tipos de comparações. Mozzer e Justi (2015) identificam a mesma lacuna em sete outros trabalhos nacionais do mesmo campo. Neste artigo, apresentaremos um conjunto de critérios extraídos de uma teoria que nos permitiu realizar essa distinção em comparações utilizadas em uma aula sobre Cinética Química.

Duas questões orientaram a pesquisa relatada neste trabalho. Que características nos permitem identificar uma comparação estabelecida por um professor como sendo uma analogia? Que articulação é estabelecida entre comparações distintas que tratam de um mesmo tema, conceito ou modelo científico? 


\section{Referencial teórico}

Em nossa pesquisa, utilizamos a Teoria do Mapeamento Estrutural (Structure-Mapping Theory) proposta originalmente por Dedre Gentner (GENTNER, 1983; GENTNER; MARKMAN, 1997). A teoria surgiu na Psicologia Cognitiva e tem sido usada no campo da Educação em Ciências para a compreensão do uso de comparações nos processos de ensino e aprendizagem dos temas científicos (ver, por exemplo, MOZZER; JUSTI, 2013, 2015). Este artigo é parte de uma tese de doutorado que faz referência a 125 trabalhos do campo das analogias na Educação em Ciências. Considerando todos esses trabalhos, não encontramos outros autores que realizam análises estruturais de analogias, de modo tão sistemático.

De acordo com essa teoria, a especificidade das analogias em relação aos outros tipos de comparação pode ser encontrada a partir da realização de um mapeamento das similaridades postuladas entre relações existentes nos dois domínios comparados: o domínio base, de um lado, e o domínio alvo, de outro. Tais relações podem ser estabelecidas entre elementos ou entre atributos desses elementos. Além das analogias, Gentner (1983) propõe a existência de outros dois tipos de comparações: similaridades de mera aparência e similaridades literais. Nas comparações de mera aparência as similaridades são estabelecidas, predominantemente, entre atributos de elementos pertencentes ao domínio base (DB) e atributos de elementos pertencentes ao domínio alvo (DA). Em outras palavras, esse tipo de comparação tem como foco algumas propriedades descritivas, tais como a forma, a cor ou o tamanho de elementos que compõem cada domínio.

Nas similaridades literais os atributos dos elementos que pertencem ao DB ainda devem corresponder a atributos de elementos que pertencem ao DA. Contudo, também deve haver similaridades entre as relações existentes entre os elementos que pertencem a cada domínio, tais como relações de hierarquia, oposição ou proporcionalidade. No caso das analogias, as correspondências são estabelecidas, predominantemente, entre relações. Assim, a existência de similaridades entre atributos dos elementos que pertencem aos dois domínios não é absolutamente necessária.

Gentner e Markman (1997) afirmam que as correspondências estabelecidas em uma analogia decorrem de um alinhamento estrutural entre os domínios comparados. O método de análise consiste em alinhar: (i) os elementos em correspondência; (ii) os atributos ou características desses elementos que são relevantes para a comparação; (iii) as relações que, dentro de cada domínio, são estabelecidas entre elementos, atributos ou relações. Ainda segundo esses autores, há três regras (ou restrições) a serem observadas para identificar uma comparação como sendo uma analogia. Paráfrases dessas regras são apresentadas a seguir, pois nós as adaptamos ao interesse e ao objeto da nossa pesquisa. A esse respeito vale lembrar, como já salientamos que a Teoria do Mapeamento Estrutural provém da Psicologia Cognitiva e que esta pesquisa investiga o uso de comparações, em sala de aula, por um professor cujo objetivo é ensinar Química. Sendo assim, os dados revelam escolhas discursivas do professor, ao invés de buscar ou postular eventuais operações cognitivas realizadas por esse sujeito durante as comparações que compõem o seu discurso.

A primeira regra a ser observada é a consistência estrutural que é constituída por duas características. A primeira é a necessidade de que cada elemento, atributo ou relação do DB tenha correspondência com um elemento, atributo ou relação do DA. A segunda característica é o estabelecimento de uma conectividade em paralelo entre os constituintes de cada domínio. 
Assim, por exemplo, quando o professor realiza uma comparação entre a distribuição das notas dos alunos em uma prova e a distribuição de energia cinética das moléculas durante uma reação química (ver Quadro 7), ele estabelece uma conectividade em paralelo entre: (i) o atributo nota mínima para aprovação dos alunos, do DB, e o atributo energia mínima para ocorrência da reação química, do DA; (ii) a relação entre os elementos nota média, alunos e prova, construída no interior do DB, e a relação entre os elementos energia média, moléculas e reação construída no interior do DA.

A segunda restrição para que uma comparação possa ser considerada uma analogia é o foco relacional. Em outras palavras, as analogias diferem das duas formas já referenciadas de comparação em virtude do foco que nelas se estabelece nas similaridades existentes entre relações estabelecidas no domínio base e outras estabelecidas do domínio alvo. A terceira e última regra é a sistematicidade. De acordo com essa regra, uma analogia mapeia, predominantemente, sistemas de relações conectados e governados por relações de ordem superior (relações entre relações), ao invés de predicados isolados constituídos apenas por atributos de elementos.

Uma consequência do que Gentner e Markman (1997) denominam de foco relacional e de princípio da sistematicidade é a compreensão de que nas analogias há um aumento da quantidade e da complexidade das similaridades estabelecidas entre relações existentes em cada domínio. Por conseguinte, do ponto de vista discursivo, a teoria proposta por Gentner nos permite considerar natural que os professores escolham usar analogias, ao invés dos outros tipos de comparações, sempre que tratam de temas mais complexos em sala de aula.

\section{Metodologia}

\section{Contexto da pesquisa e forma de registro das aulas observadas}

Observamos e registramos em áudio e vídeo as aulas de um professor de Química em uma instituição privada de ensino superior localizada em Belo Horizonte, Minas Gerais, durante os meses de fevereiro a junho de 2014. Trata-se da mesma instituição na qual um dos autores deste artigo trabalhava na época da realização da pesquisa de campo. As aulas faziam parte da disciplina Elementos de Físico-química, que compõe a matriz curricular de um curso de Farmácia. A turma acompanhada era constituída por 32 alunos adultos que estavam cursando o $2^{\circ}$ período. Por meio da assinatura de um Termo de Consentimento Livre e Esclarecido, o professor e os alunos nos autorizaram a realização da pesquisa naquele ambiente. A disciplina era ministrada em quatro aulas semanais (50 min/aula) concentradas em um único turno e dia da semana. Não conseguimos acompanhar e registrar todas as aulas em função de diversos fatores. Registramos sete encontros semanais, totalizando 822 minutos de gravação.

\section{O sujeito da pesquisa}

O sujeito da pesquisa atua há mais de 30 anos no ensino de Química, tanto como professor do Ensino Médio, quanto do Ensino Superior. Ele também desempenha atividades de coordenação pedagógica, é autor de livros didáticos de Química e desenvolve pesquisas no ensino de Ciências, na condição de doutor formado por um programa de pós-graduação de 
uma Universidade Federal. Além da facilidade de acesso ao professor e à instituição de ensino na qual ele trabalhava, a escolha por esse sujeito levou em consideração uma rica entrevista ${ }^{3}$ em que ele abordou o uso de analogias no ensino de Química.

Apresentamos ao professor o projeto da pesquisa e ele assinou o termo de consentimento livre e esclarecido. Considerando a naturalidade e a facilidade com que o professor utilizou analogias durante o período em que fizemos as observações, achamos pouco provável que o uso desse recurso por parte desse sujeito possa ser explicado pelo simples fato deste saber qual era o real interesse de pesquisa.

Quando surgiu a oportunidade de realizar a pesquisa na sala de aula de um professor com tal currículo, vislumbramos que a investigação poderia colocar-nos em contato com uma prática potencialmente exemplar, no que diz respeito ao uso de analogias como recursos didáticos de ensino. Criamos assim a expectativa de que os resultados da pesquisa poderiam contribuir para a prática pedagógica de outros professores ou para desnudar aspectos a serem levados em consideração na formação inicial de professores, no que diz respeito ao uso de analogias e outros tipos de comparação nas salas de aula de Ciências.

\section{Posicionamento das câmeras e software usado na análise}

Seguindo a orientação da pesquisa realizada por Kress et al. (2001), usamos duas câmeras de vídeo. A câmera principal foi posicionada no fundo da sala de aula e foi usada para registrar as ações do professor. A segunda câmera foi posicionada na frente da sala, alinhada com a diagonal da sala e situada ao lado do quadro branco. Essa câmera foi direcionada para os alunos, a fim de capturar suas ações ou reações às ações do professor. Em um caderno de campo, registramos várias observações a respeito das interações entre os estudantes e o professor que não tínhamos certeza de termos capturado nas gravações em vídeo ou que intuímos como sendo potencialmente importantes para a pesquisa. Esse caderno também serviu ao registro de comentários e hipóteses sobre as características e funções discursivas das comparações que surgiram durante nossa permanência na sala de aula.

A descrição e a transcrição dos vídeos foram realizadas por meio de um software específico para pesquisas qualitativas em Educação: o NVivo ${ }^{\circledR}$ for $W$ indows (10 ${ }^{\mathrm{a}}$ versão). Esse software nos permitiu assistir cuidadosamente cada registro produzido, mediante o uso de botões para avanço ou recuo das cenas em velocidade normal, acima do normal ou em câmera lenta. Também pudemos transcrever falas de alguns trechos de vídeo selecionados com um recurso que permite a sincronização das transcrições com o vídeo.

\section{Padrão usado na transcrição das falas}

A transcrição das falas foi realizada a partir de uma adaptação do padrão adotado por Buty e Mortimer (2008). Assim: a barra / indica pausas breves; parênteses ( ) indicam pausas

\footnotetext{
${ }^{3}$ Entrevista concedida a um canal de comunicação via satélite para uma rede privada de ensino na qual o professor, sujeito desta pesquisa, atuava como coordenador pedagógico para o ensino de Ciências.
} 
mais longas cuja duração é dada em segundos; colchetes [] indicam a ocorrência de discursos simultâneos; barras duplas // sinalizam a interrupção do discurso de um sujeito por uma enunciação realizada por outro sujeito; parênteses duplos $(())$ servem à inserção de comentários que explicitam a forma como interpretamos aquilo que transcrevemos; reticências ... indicam situações em que um sujeito não completou sua enunciação; reticências colocadas entre colchetes [...] indicam trechos de fala não transcritos (trechos inaudíveis ou não analisados na pesquisa); pontos de exclamação (!) e interrogação (?) indicam, respectivamente, mudanças de entonação associadas a afirmações enfáticas e perguntas. Com o negrito destacamos enunciados que faziam menção ao DB de uma comparação e com o sublinhado os enunciados associados ao DA.

A partir da identificação dos enunciados negritados e dos sublinhados, construímos quadros com o alinhamento dos elementos, atributos e relações presentes em cada domínio e que foram postos em correspondência. A partir desse alinhamento verificamos se havia uma conectividade em paralelo entre os domínios. Os dados apresentados neste artigo incluem transcrições da fala do professor, e os quadros que apresentam os mapeamentos estruturais trazem paráfrases ao invés da transcrição literal do que este disse. A escolha por usar paráfrases nos quadros decorre da intenção de sinalizar, o mais claramente possível, a existência das conectividades em paralelo entre os domínios que compuseram as comparações realizadas pelo professor.

\section{Padrão do mapeamento estrutural das comparações}

Decidimos usar setas bidirecionais para representar as correspondências entre elementos, atributos ou relações que constituem cada domínio. Uma correspondência estabelecida entre um elemento do DB e outro elemento do DA é acompanhada pela letra E (maiúscula) e por um número. Uma correspondência entre atributos é acompanhada pela letra A e por um número. Atributos e elementos estruturais irrelevantes para a comparação não foram incluídos no mapeamento, exceto quando implicavam em alguma limitação da comparação destacada pelo professor.

No mapeamento estrutural apresentado neste artigo identificamos relações estruturais, causais e de proporcionalidade. Relações entre elementos ou atributos são chamadas de relações de primeira ordem. Relações de segunda ordem são aquelas estabelecidas entre duas relações de primeira ordem ou entre uma relação de primeira ordem e um elemento ou atributo. O termo ordem superior foi usado para nomear uma relação que inclui pelo menos uma relação de segunda ordem.

As relações são acompanhadas pela letra $\mathrm{r}$ (minúscula) ou $\mathrm{R}$ (maiúscula). A letra minúscula representa uma relação de primeira ordem, enquanto a maiúscula representa uma relação de segunda ordem ou de ordem superior. $\mathrm{Na}$ codificação de uma relação são enumerados os atributos ou elementos a ela associados. Por exemplo, o código $r_{1}\left(E_{2}, E_{1}\right)$ indica uma relação de primeira ordem entre elementos correspondentes do DB e do DA. Da mesma forma, o código $r_{2}\left(A_{2}, A_{1}\right)$ indica uma relação de primeira ordem que, todavia, tem como foco atributos correspondentes dos dois domínios. Já o código $\mathrm{R}_{1}\left(\mathrm{r}_{2}, \mathrm{r}_{1}\right)$ indica uma correspondência realizada entre as relações $r_{2}$ e $r_{1}$, ou seja, indica uma correspondência que identificamos como uma relação de segunda ordem.

O padrão que criamos para representar a estrutura de uma comparação, embora seja diferente daquele usado por Gentner (1983), atende ao requisito de identificar não somente 
elementos ou atributos similares em cada domínio, mas também as relações estabelecidas entre eles, bem como as relações de ordem superior postuladas entre relações de primeira ordem. Nosso padrão nos parece mais amigável em relação ao padrão usado pela autora supracitada, no sentido de que é menos dependente de notações tipicamente utilizadas na álgebra e menos legíveis aos não iniciados nessa disciplina.

O Quadro 1 apresenta os símbolos gráficos usados no nosso padrão de transcrição e as correspondências entre: elementos $\left(E_{n}\right)$, atributos $\left(A_{n}\right)$, relações de primeira ordem $\left(r_{n}\right)$ e relações de maior complexidade $\left(\mathrm{R}_{\mathrm{n}}\right)$. Qualquer correspondência que envolva uma limitação da comparação foi identificada pela presença da letra X sobre a posição mediana de uma seta bidirecional. $\mathrm{O}$ mesmo sinal também indica correspondências com ênfase negativa, isto é, que sinalizam a existência de uma diferença entre os dois domínios.

Quadro 1. Símbolos usados na representação das correspondências

\begin{tabular}{|c|c|c|}
\hline Domínio Base & Correspondências & Domínio Alvo \\
\hline Elemento análogo & $\hookrightarrow \mathrm{E}_{\mathrm{n}} \longrightarrow$ & Elemento alvo \\
\hline $\begin{array}{l}\text { Um dos elementos que compõem } \\
\text { o DB }\end{array}$ & $\begin{array}{l}\text { Correspondências entre } \\
\text { elementos (E) }\end{array}$ & $\begin{array}{c}\text { Um dos elementos que compõem } \\
\text { o DA }\end{array}$ \\
\hline Atributos do elemento análogo & $\stackrel{\mathrm{A}_{\mathrm{n}}}{\longrightarrow}$ & Atributos do elemento alvo \\
\hline $\begin{array}{l}\text { Predicados de um elemento do } \\
\text { DB baseados em uma única } \\
\text { característica }\end{array}$ & $\begin{array}{l}\text { Correspondências entre } \\
\text { atributos (A) }\end{array}$ & $\begin{array}{l}\text { Predicados de um elemento do } \\
\text { DA baseados em uma única } \\
\text { característica }\end{array}$ \\
\hline Relações de $1^{\text {a }}$ ordem & $\hookrightarrow \quad \mathrm{r}_{\mathrm{n}} \longrightarrow$ & Relações de $1^{\text {a }}$ ordem \\
\hline $\begin{array}{c}\text { Relações entre dois ou mais } \\
\text { elementos do DB ou entre suas } \\
\text { características }\end{array}$ & $\begin{array}{l}\text { Correspondências } \\
\text { entre relaçôes de menor } \\
\text { complexidade } \mathbf{( r )}\end{array}$ & $\begin{array}{c}\text { Relações entre dois ou mais } \\
\text { elementos do DA ou entre suas } \\
\text { características }\end{array}$ \\
\hline Relações de ordem superior & $\longleftarrow \mathrm{R}_{\mathrm{n}} \longrightarrow$ & Relações de ordem superior \\
\hline $\begin{array}{l}\text { Relações estabelecidas entre } \\
\text { relações previamente postuladas } \\
\text { entre elementos do DB }\end{array}$ & $\begin{array}{l}\text { Correspondências entre } \\
\text { relaçôes de maior complexidade } \\
\mathbf{( R )}\end{array}$ & $\begin{array}{l}\text { Relações estabelecidas entre } \\
\text { relações previamente postuladas } \\
\text { entre elementos do DA }\end{array}$ \\
\hline Atributo ou relação do DB & $\longrightarrow \quad \longrightarrow$ & Atributo ou relação do DA \\
\hline $\begin{array}{c}\text { Característica ou relação presente } \\
\text { no DB que não se aplica ou que } \\
\text { não pode ser transferida para o } \\
\text { alvo }\end{array}$ & $\begin{array}{l}\text { Limitação da comparação; } \\
\text { diferença alinhável }\end{array}$ & $\begin{array}{l}\text { Característica ou relação presente } \\
\text { no DA que é diferente da base }\end{array}$ \\
\hline
\end{tabular}

Fonte: elaborado pelos autores. 
Ferry, A. S.; Figueirêdo e Paula, H.

\section{Resultados e discussão}

\section{Descrição da aula e caracterização das comparações}

No encontro de onde extraímos as comparações analisadas neste artigo, o professor abordou ideias centrais da teoria das colisões para as reações químicas e destacou a temperatura como um fator capaz de provocar alterações na taxa de reação. Nesse contexto, o professor construiu 13 comparações. Em nenhum outro encontro foram estabelecidas tantas comparações. No conjunto dos outros seis encontros ele estabeleceu 15 comparações. Apresentamos a seguir uma linha do tempo que construímos com a finalidade de localizar sequencialmente as comparações enunciadas pelo professor durante o $5^{\circ}$ encontro. As 13 comparações foram identificadas por letras do alfabeto grafadas em maiúsculo. No Quadro 2 usamos as mesmas letras para descrever cada comparação, por meio da identificação do intervalo de tempo gasto pelo professor em cada uma delas, da explicitação de seus domínios base e alvo, bem como da apresentação de comentários complementares. A linha do tempo da aula sobre Cinética Química do encontro ocorrido no dia 07/05/14 apresenta a identificação das comparações enunciadas por meio de letras.

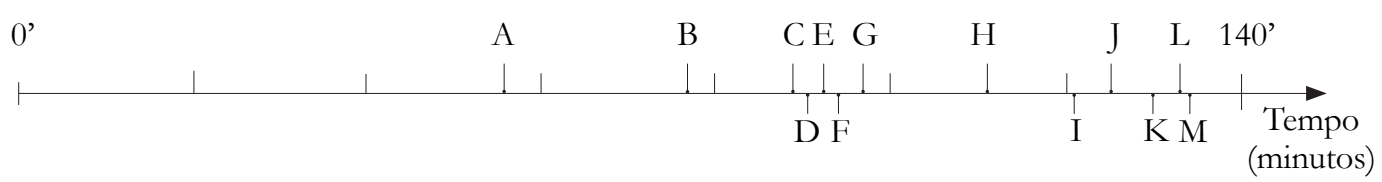

Quadro 2. Comparações enunciadas durante as aulas do encontro do dia 07 de maio de 2014

\begin{tabular}{|c|c|c|c|}
\hline $\begin{array}{c}\text { Comparação / } \\
\text { Período }\end{array}$ & Domínio base & Domínio alvo & Comentários \\
\hline $\begin{array}{c}\mathbf{A} \\
\left(55^{\prime} 27^{\prime \prime}-58^{\prime} 02^{\prime \prime}\right)\end{array}$ & $\begin{array}{l}\text { Velocidade de } \\
\text { um carro }\end{array}$ & $\begin{array}{l}\text { Velocidade de } \\
\text { uma reação } \\
\text { química }\end{array}$ & \multirow{2}{*}{$\begin{array}{l}\text { Ao explorar a cinética das reações, o } \\
\text { professor introduziu o conceito de } \\
\text { velocidade por meio da comparação } \\
\text { A. Posteriormente, antes de deduzir } \\
\text { uma expressão da velocidade que não } \\
\text { dependesse de uma substância específica, } \\
\text { ele estabeleceu a comparação B. }\end{array}$} \\
\hline $\begin{array}{c}\mathbf{B} \\
\left(77^{\prime} 00^{\prime \prime}-78^{\prime} 05^{\prime \prime}\right)\end{array}$ & $\begin{array}{l}\text { Velocidade } \\
\text { de diferentes } \\
\text { partes de um } \\
\text { carro }\end{array}$ & $\begin{array}{l}\text { Velocidade de } \\
\text { consumo e de } \\
\text { produção de } \\
\text { substâncias }\end{array}$ & \\
\hline $\begin{array}{c}\mathbf{C} \\
\left(87^{\prime} 05^{\prime \prime}-87^{\prime} 43^{\prime \prime}\right)\end{array}$ & $\begin{array}{l}\text { Pele sobre o } \\
\text { corpo humano }\end{array}$ & $\begin{array}{l}\text { Camada de } \\
\text { tinta sobre } \\
\text { uma superfície } \\
\text { metálica }\end{array}$ & $\begin{array}{c}\text { Expressão de caráter metafórico que não } \\
\text { será analisada neste artigo. }\end{array}$ \\
\hline $\begin{array}{c}\mathbf{D} \\
\left(88^{\prime} 50^{\prime \prime}-89^{\prime} 33^{\prime \prime}\right) \\
\left(97^{\prime} 20^{\prime \prime}-97^{\prime} 23^{\prime \prime}\right)\end{array}$ & $\begin{array}{l}\text { Brincadeira com } \\
\text { uma bola sendo } \\
\text { jogada contra } \\
\text { uma parede }\end{array}$ & $\begin{array}{l}\text { Colisões entre } \\
\text { partículas } \\
\text { durante uma } \\
\text { reação química }\end{array}$ & $\begin{array}{l}\text { A comparação } \mathbf{D} \text { foi enunciada quando o } \\
\text { professor introduziu a teoria das colisões. } \\
\text { Essa comparação está relacionada com a } \\
\text { F e mapeada no Quadro } 3 .\end{array}$ \\
\hline $\begin{array}{c}\mathbf{E} \\
\left(90^{\prime} 42^{\prime \prime}-90^{\prime} 51^{\prime \prime}\right)\end{array}$ & Esferas & $\begin{array}{c}\text { Moléculas } \\
\text { "monoatômicas" }\end{array}$ & Relação não analisada neste artigo. \\
\hline
\end{tabular}


Mapeamento estrutural de analogias enunciadas em uma aula ...

Quadro 2. continuação

\begin{tabular}{|c|c|c|c|}
\hline $\begin{array}{c}\text { Comparação / } \\
\text { Período }\end{array}$ & Domínio base & Domínio alvo & Comentários \\
\hline $\begin{array}{c}\mathbf{F} \\
\left(91^{\prime} 000^{\prime \prime}-92^{\prime} 56^{\prime \prime}\right) \\
\left(93^{\prime} 28^{\prime \prime}-94^{\prime} 42^{\prime \prime}\right)\end{array}$ & $\begin{array}{l}\text { Situações em } \\
\text { um jogo de } \\
\text { sinuca }\end{array}$ & $\begin{array}{l}\text { Situações } \\
\text { previstas pela } \\
\text { teoria das } \\
\text { colisões }\end{array}$ & $\begin{array}{l}\text { A comparação } \mathbf{F} \text {, mapeada no Quadro } \\
\text { 4, assim como a D, foi enunciada no } \\
\text { contexto da teoria das colisões. }\end{array}$ \\
\hline $\begin{array}{c}\mathbf{G} \\
\left(97^{\prime} 40^{\prime \prime}-97^{\prime} 58^{\prime \prime}\right)\end{array}$ & $\begin{array}{l}\text { Acidentes de } \\
\text { trânsito }\end{array}$ & $\begin{array}{c}\text { Choques entre } \\
\text { moléculas }\end{array}$ & $\begin{array}{l}\text { A comparação } \mathbf{G} \text { foi enunciada a fim de } \\
\text { evidenciar a grande quantidade de energia } \\
\text { envolvida nas colisões. Essa ideia foi } \\
\text { retomada na comparação } \mathbf{J} .\end{array}$ \\
\hline $\begin{array}{c}\mathbf{H} \\
\left(110^{\prime} 30^{\prime \prime}-\right. \\
\left.112 ’ 33^{\prime \prime}\right)\end{array}$ & $\begin{array}{l}\text { Deslocamento } \\
\text { de um veículo } \\
\text { em um aclive }\end{array}$ & $\begin{array}{l}\text { Representação } \\
\text { gráfica da } \\
\text { energia de } \\
\text { ativação de uma } \\
\text { reação química }\end{array}$ & $\begin{array}{c}\text { O professor retomou aspectos da } \\
\text { teoria das colisões para relacioná-los } \\
\text { com a representação gráfica da entalpia } \\
\text { do complexo ativado e a energia de } \\
\text { ativação. Nesse contexto ele enunciou } \\
\text { a comparação } \mathbf{H} \text { cujo mapeamento } \\
\text { estrutural não será apresentado neste } \\
\text { artigo. }\end{array}$ \\
\hline $\begin{array}{c}\mathbf{I} \\
\left(121^{\prime} 11^{\prime \prime},-\right. \\
\left.121^{\prime} 48^{\prime \prime}\right)\end{array}$ & $\begin{array}{l}\text { Notas obtidas } \\
\text { por estudantes } \\
\text { em uma } \\
\text { avaliação }\end{array}$ & $\begin{array}{l}\text { Movimentação } \\
\text { de moléculas em } \\
\text { um sistema }\end{array}$ & $\begin{array}{l}\text { A comparação I (Quadro 6) foi } \\
\text { enunciada para abordar o conceito } \\
\text { de temperatura e foi retomada na } \\
\text { construção da comparação } \mathbf{M} \text {. }\end{array}$ \\
\hline $\begin{array}{c}\mathbf{J} \\
\left(124^{\prime} 24^{\prime \prime}-\right. \\
\left.125^{\prime} 02^{\prime \prime}\right)\end{array}$ & $\begin{array}{l}\text { Aumento da } \\
\text { quantidade de } \\
\text { acidentes nas } \\
\text { estradas }\end{array}$ & $\begin{array}{l}\text { Aumento da } \\
\text { quantidade de } \\
\text { choques entre } \\
\text { moléculas }\end{array}$ & $\begin{array}{l}\text { A comparação } \mathbf{J} \text { foi enunciada na } \\
\text { apresentação de uma relação matemática } \\
\text { entre o aumento da temperatura e o } \\
\text { aumento da velocidade das reações } \\
\text { químicas. }\end{array}$ \\
\hline $\begin{array}{c}\mathbf{K} \\
\left(128^{\prime} 00^{\prime \prime}-\right. \\
\left.128^{\prime} 42^{\prime \prime}\right)\end{array}$ & $\begin{array}{l}\text { Função de uma } \\
\text { máquina do } \\
\text { tempo }\end{array}$ & $\begin{array}{l}\text { Função de uma } \\
\text { geladeira }\end{array}$ & $\begin{array}{l}\text { Comparação menos elaborada com o } \\
\text { propósito de abordar a função de uma } \\
\text { geladeira na conservação de alimentos. }\end{array}$ \\
\hline $\begin{array}{c}\mathbf{L} \\
\left(1300^{\prime} 40^{\prime \prime}-\right. \\
\left.1300^{\prime} 58^{\prime \prime}\right) \\
\end{array}$ & $\begin{array}{l}\text { Forma de um } \\
\text { sino }\end{array}$ & $\begin{array}{c}\text { Forma de um } \\
\text { gráfico } \\
\text { (curva gaussiana) }\end{array}$ & $\begin{array}{l}\text { Comparação por mera aparência, } \\
\text { baseada unicamente em um atributo dos } \\
\text { elementos em correspondência. }\end{array}$ \\
\hline $\begin{array}{c}\mathbf{M} \\
\left(131^{\prime} 04^{\prime \prime}-\right. \\
\left.135^{\prime} 37^{\prime \prime}\right)\end{array}$ & $\begin{array}{l}\text { Distribuição } \\
\text { das notas dos } \\
\text { alunos em uma } \\
\text { prova }\end{array}$ & $\begin{array}{l}\text { Distribuição da } \\
\text { energia cinética } \\
\text { de moléculas em } \\
\text { reação química }\end{array}$ & $\begin{array}{c}\text { A comparação M (Quadro 7) retomou as } \\
\text { ideias da comparação I e foi construída } \\
\text { no contexto da elaboração de um gráfico } \\
\text { (ver Figura 1). }\end{array}$ \\
\hline
\end{tabular}

Fonte: elaborado pelos autores.

A identificação dos domínios base e alvo das 13 comparações no Quadro 2 mostra que as comparações A e B, D e F, G e J, assim como o par I e M, estão relacionadas entre si. Para compreender a extensão das relações entre elas recorreremos ao mapeamento estrutural 
Ferry, A. S.; Figueirêdo e Paula, H.

dessas comparações. Considerando as limitações de espaço para o presente artigo, tivemos que analisar apenas dois pares de comparações: D-F e I-M. O critério usado nessa escolha foi a complexidade dessas quatro comparações. Os quadros a seguir apresentam os mapeamentos estruturais que fizemos. Antecedendo cada quadro, apresentamos uma transcrição da fala do professor na qual o negrito destaca os enunciados associados ao domínio base e o sublinhado àqueles associados ao domínio alvo.

\section{Comparações D \& F}

As comparações $\mathbf{D}$ e $\mathbf{F}$ foram enunciadas após o professor ter retomado conceitos da teoria das colisões.

((88’50”)) [...] ((COMPARAÇÃO D)) então veja bem / nós temos um primeiro ponto importante / nós acreditamos que toda a matéria é formada por átomos e / no caso mais importante as moléculas / essas moléculas estão em movimento e o que vai explicar as transformacõoes dos materiais é que as moléculas... colidem entre si / (2s) / mas será que qualquer colisão vai levar a uma transformação? / será que qualquer colisão vai levar o reagente a virar produto? / não / colisões vão acontecer / a maioria das colisões não altera os materiais / é como uma bola que a gente joga na parede / bate na parede / mas a parede continua parede e a bola continua / ((sendo)) bola ((89’33’')) / na verdade / a colisão que leva à reação é chamada de colisão eficaz ou também chamada de colisão efetiva / (3s) / acontece toda sorte de colisões quando os reagentes estão em contato / particularmente [...] ((expressão não compreendida)) / mas / (2s) / não é toda colisão que vai levar à transformação / é uma colisão bem especial / essa colisão é chamada de colisão eficaž, colisão efetiva / [...] / então, geralmente quando a gente quer dar uma dimensão de um choque eficaz. I nós criamos um modelo / ou seja / ((COMPARAÇÃO F - 91'00")) pra gente poder comparar / que é.. / vamos dizer assim... / no caso... é... / uma analogia / um modelo analógico / de algo que acontece por colisão / e todo mundo conhece um jogo que a gente chama de bilhar ou sinuca / é um jogo que na verdade ele funciona à base de uma colisão / uma bolinha branca que tem que colidir com outra bolinha / e essa outra bolinha após a colisão tem que se dirigir a uma determinada caçapa / (1s) / então nós comparamos de certa maneira a colisão eficaz / a colisão efetiva / com essa situação do jogo de bilhar / o quê que é necessário para que a colisão seja efetiva? / no jogo de bilhar a colisão efetiva é aquela que a bolinha vai pra caçapa / qualquer outra colisão que não fizer isso é uma colisão que... não tem praticidade pro jogo / então nós vamos dizer o seguinte / a primeira coisa fundamental é que a geometria / o momento do choque / seja uma geometria favorável / (6s) / ou seja / se a gente pensar no jogo / não é atoa que um jogador ele fica posicionando olhando $o$ jogo / pensando na estratégia para fazer o movimento / pra que a colisão da bola branca e a bola que ele quer colocar na caçapa tenha geometria adequada / porque depois da colisão a bola tem 
que ir num determinado... / vamos dizer assim / é... sentido / uma determinada orientação / que é exatamente o caminho da caçapa / (2s) / então a geometria / ou seja / o momento / a maneira como o choque se dá $\angle$ tem que ser favorável para a transformacão / e a maioria dos choques não tem essa geometria favorável ((92'56”)) / depois nós vamos tentar entender isso melhor / ( (a continuação dessa comparação será apresentada mais adiante)).

O Quadro 3 apresenta o mapeamento estrutural da comparação $\mathbf{D}$ que está situada no início do trecho de fala transcrito acima.

Quadro 3. Mapeamento estrutural da comparação $\mathbf{D}$ que trata de um aspecto da teoria das colisões

\begin{tabular}{|c|c|c|}
\hline Domínio Base & Correspondências & Domínio Alvo \\
\hline Bola & $\mathrm{E}_{1}$ & Partículas (átomos ou moléculas) \\
\hline Parede & $\mathrm{E}_{2}$ & Partículas (átomos ou moléculas) \\
\hline $\begin{array}{c}\text { A parede (e a bola) pode } \\
\text { sofrer alterações (por exemplo, } \\
\text { deformações) }\end{array}$ & $\mathrm{A}_{1}\left(\mathrm{E}_{2}\right)$ & $\begin{array}{c}\text { As partículas podem sofrer } \\
\text { alterações (podem reagir uma com } \\
\text { a outra) }\end{array}$ \\
\hline A bola colide contra a parede & $\mathrm{r}_{1}\left(\mathrm{E}_{1}, \mathrm{E}_{2}\right)$ & Uma partícula colide contra outra \\
\hline $\begin{array}{l}\text { A maioria das colisões entre bolas } \\
\text { e paredes não deforma esses } \\
\text { objetos; desse ponto de vista, são } \\
\text { colisões ineficazes }^{*}{ }^{*}\end{array}$ & $\mathrm{R}_{1}\left(\mathrm{r}_{1}, \mathrm{~A}_{1}\right)$ & $\begin{array}{l}\text { A maioria das colisões entre } \\
\text { partículas não produz alterações } \\
\text { (reações químicas) nos materiais; } \\
\text { são colisões ineficazes }\end{array}$ \\
\hline
\end{tabular}

${ }^{*}$ No DA a relação $R_{1}$ é enunciada explicitamente. No DB a relação $R_{1}$ não é enunciada, mas pode ser inferida. Fonte: elaborado pelos autores.

O mapeamento estrutural da comparação $\mathbf{D}$ evidencia uma relação de primeira or$\operatorname{dem}\left(\mathrm{r}_{1}\right)$ e outra de segunda ordem $\left(\mathrm{R}_{1}\right)$. $\mathrm{O}$ foco da comparação não se restringe a elementos ou atributos de elementos pertencentes a cada domínio. Ao invés disso, o destaque está na correspondência de relações estabelecidas entre elementos do domínio base e relações estabelecidas entre elementos do domínio alvo. De acordo com a teoria de mapeamento estrutural essa característica da comparação permite identificá-la como uma analogia, isto é, como uma comparação com consistência estrutural e foco relacional. A mesma característica distingue essa comparação daquilo que Gentner e Markman (1997) postulam como comparações por mera aparência e similaridades literais.

O mapeamento revela que um elemento do domínio alvo (partículas) se refere a dois diferentes elementos do domínio base (bola e parede), o que poderia implicar na falta de correspondência um a um, que é prevista pela regra de consistência estrutural. Todavia, nos dois domínios, a relação $r_{1}$ coloca em destaque a colisão entre dois objetos. Desde esse ponto de vista, não há perda de consistência estrutural na analogia. 
A comparação $\mathbf{F}$ foi iniciada após 91 minutos do começo do encontro. Ao iniciá-la, o próprio professor afirmou estar construindo uma analogia. Essa classificação da comparação é reafirmada por meio da análise apresentada no Quadro 4.

Quadro 4. Mapeamento estrutural da comparação $\mathbf{F}$ que trata do papel da geometria dos choques na teoria das colisões

\begin{tabular}{|c|c|c|}
\hline Domínio Base & Correspondências & Domínio Alvo \\
\hline Bolas de sinuca & $\mathrm{E}_{1}$ & Moléculas \\
\hline Jogo de sinuca & $\mathrm{E}_{2}$ & Reação química \\
\hline Movimento das bolas & $\mathrm{E}_{3}$ & Movimento das moléculas \\
\hline $\begin{array}{l}\text { As bolas podem se mover em várias } \\
\text { direções (dependendo da tacada) }\end{array}$ & $\mathrm{A}_{1}\left(\mathrm{E}_{3}\right)$ & $\begin{array}{l}\text { As moléculas se movimentam em } \\
\text { diferentes direções e sentidos }\end{array}$ \\
\hline $\begin{array}{c}\text { Por causa do movimento das bolas, } \\
\text { elas podem colidir umas com as } \\
\text { outras. }\end{array}$ & $\mathrm{r}_{1}\left(\mathrm{E}_{3}, \mathrm{E}_{1}\right)$ & $\begin{array}{l}\text { Por causa do movimento das } \\
\text { moléculas elas podem colidir umas } \\
\text { com as outras. }\end{array}$ \\
\hline $\begin{array}{l}\text { A direção dos movimentos das } \\
\text { bolas gera colisões com diferentes } \\
\text { geometrias. }\end{array}$ & $\mathrm{R}_{1}\left(\mathrm{r}_{1}, \mathrm{~A}_{1}\right)$ & $\begin{array}{l}\text { A direção dos movimentos das } \\
\text { moléculas gera colisões com } \\
\text { diferentes geometrias. }\end{array}$ \\
\hline $\begin{array}{c}\text { Há direções no movimento das } \\
\text { bolas que favorecem a geometria } \\
\text { do choque e geram colisões efetivas } \\
\text { (bola na caçapa). }\end{array}$ & $\mathrm{R}_{2}\left(\mathrm{r}_{1}, \mathrm{~A}_{1}\right)$ & $\begin{array}{l}\text { Há direções no movimento } \\
\text { das moléculas que favorecem a } \\
\text { geometria do choque e geram } \\
\text { colisões efetivas (reações químicas). }\end{array}$ \\
\hline $\begin{array}{l}\text { Durante o jogo de sinuca, a } \\
\text { quantidade de choques com } \\
\text { geometria desfavorável é maior } \\
\text { que a quantidade de choques com } \\
\text { geometria favorável. }{ }^{(*)}\end{array}$ & $\mathrm{R}_{3}\left(\mathrm{R}_{1}, \mathrm{R}_{2}, \mathrm{E}_{2}\right)$ & $\begin{array}{l}\text { Durante a ocorrência da reação } \\
\text { química, a quantidade de choques } \\
\text { com geometria desfavorável é maior } \\
\text { que a quantidade de choques com } \\
\text { geometria favorável. }\end{array}$ \\
\hline $\begin{array}{l}\text { O maior número de colisões com } \\
\text { geometria desfavorável gera um } \\
\text { grande número de colisões que não } \\
\text { conduzem as bolas para a caçapa. }\end{array}$ & $\mathrm{R}_{4}\left(\mathrm{R}_{3}, \mathrm{R}_{2}\right)$ & $\begin{array}{l}\text { O maior número de colisões com } \\
\text { geometria desfavorável gera um } \\
\text { grande número de colisões que não } \\
\text { provocam reações químicas. }\end{array}$ \\
\hline $\begin{array}{c}\text { Uma bolinha alcança uma caçapa } \\
\text { após ter sido atingida por outra em } \\
\text { uma geometria favorável }\end{array}$ & $\mathrm{R}_{5}\left(\mathrm{R}_{2}, \mathrm{R}_{1}\right)$ & $\begin{array}{l}\text { Uma molécula reage com outra após } \\
\text { ter sido atingida em uma geometria } \\
\text { favorável }\end{array}$ \\
\hline
\end{tabular}

(*) Assim como no caso da relação $\mathrm{R}_{1}$ mencionada no Quadro 3, a relação $\mathrm{R}_{3}$ mencionada no Quadro 4 não foi enunciada pelo professor quando ele caracterizou o DB. Contudo, a presença dessas relações no DB pode ser inferida em ambos os casos, a partir de uma análise lógica baseada no conhecimento do analista acerca dos elementos e das relações que estruturam o DB e o DA.

Fonte: elaborado pelos autores. 
A comparação construída pelo professor entre situações que ocorrem em um jogo de sinuca e as colisões que ocorrem entre moléculas durante uma reação química pode ser compreendida como uma analogia estruturalmente consistente, sistemática e com foco essencialmente relacional, tendo em vista as cinco relações de ordem superior identificadas no Quadro 4 pelos símbolos $\mathrm{R}_{1}$ a $\mathrm{R}_{5}$. Fazendo uma análise dessas relações notamos que $\mathrm{R}_{1}$ e $\mathrm{R}_{2}$ são relações de segunda ordem baseadas no atributo $A_{1}$ e na relação de primeira ordem $r_{1}$. Tanto $\mathrm{R}_{1}$ e $\mathrm{R}_{2}$ podem ser classificadas como relações causais: $\mathrm{R}_{1}$ explica a diversidade das colisões possíveis e $R_{2}$ a existência de colisões efetivas ou não efetivas, segundo o critério pertinente a cada domínio (encaçapar a bola no jogo de sinuca ou transformar reagente em produto na reação química). $R_{3}, R_{4}$ e $R_{5}$ são três relações de ordem superior: (i) $R_{3}$ compara quantidades de choques com geometria favorável ou desfavorável; (ii) $\mathrm{R}_{4}$ vincula a quantidade de choques com geometria desfavorável e a quantidade de choques ineficazes; (iii) $\mathrm{R}_{5}$ descreve o resultado dos choques com geometria favorável.

\section{Continuação da Comparação F}

((93’05”)) / e uma segunda situação aqui / uma condição que é necessária e insuficiente / ou seja / uma sozinha não adianta / é que tenha uma energia minima necessária / (14s) / ((continuação da COMPARAÇÃO F - 93'28')) ora porque / pegando a situação do jogo / não adianta a colisão ter sido numa geometria favorável se a bolinha parar no meio do caminho / (2s) / ela tem que sair / não só na direção correta / mas com uma energia mínima pra chegar até a caçapa e entrar dentro da caçapa / pode ter MAIS energia do que isso / o que não pode é ter... / [menos] / menos / eu tenho que ter uma energia mínima necessário pra isso / (2s) / no nosso caso aqui / voltando à reacão / diferentemente do jogo / o jogo nos ajuda ((a entender as reações químicas)), mas a situação aqui é bem distinta do jogo ((93'57")) / nós temos uma situação que nós temos que entender o seguinte / ora / quando eu tenho uma reacão acontencendo / olha aí a ideia / nós temos na verdade / antes de virar produto / nós temos aqui o momento do choque / (2s) / entre os reagentes / e se o choque for um choque eficaz / eu vou ter os... produtos / (3s) / qual a diferença entre reagentes e produtos? / ora / as ligacoes que eu tenho nos reagentes / são diferentes das ligacões que eu tenho nos produtos ((94'42”)) / [...] / ((96’53')) no momento do choque / tem que começar a quebrar a ligação dos reagentes e tem que começar a ter a formação das novas ligações que estão nos produtos / então esse momento do choque / que é bom pensar que o choque é efetivo / tá certo? / eu vou colocar aqui como um intermediário ((complexo ativado)) / se eu não tiver um choque efetivo volta a ser reagente / e não vira produto / ((retomada da COMPARAÇÃO D - 97'20”)) é a bolinha que bateu na parede e voltou [...]

O Quadro 5 apresenta o mapeamento estrutural das novas correspondências estabelecidas na comparação $\mathbf{F}$. 
Quadro 5. Mapeamento estrutural da continuação da comparação $\mathbf{F}$ que trata do papel da energia dos choques na teoria das colisões

\begin{tabular}{|c|c|c|}
\hline Domínio Base & Correspondências & Domínio Alvo \\
\hline Energia das bolas de sinuca & $\mathrm{A}_{2}\left(\mathrm{E}_{1}\right)$ & Energia das moléculas \\
\hline $\begin{array}{l}\text { "Não adianta a colisão ter sido numa } \\
\text { geometria favorável se a bolinha parar no } \\
\text { meio do caminho" }\end{array}$ & $\mathrm{R}_{6}\left(\mathrm{R}_{1}, \mathrm{~A}_{2}\right)$ & $\begin{array}{l}\text { Não adianta a colisão entre as } \\
\text { moléculas ter uma geometria } \\
\text { favorável se a energia não for } \\
\text { suficiente para provocar a reação }\end{array}$ \\
\hline $\begin{array}{l}\text { Uma colisão entre bolas de sinuca } \\
\text { será efetiva se houver geometria } \\
\text { favorável e energia suficiente para } \\
\text { uma bola ir à caçapa }\end{array}$ & $\mathrm{R}_{7}\left(\mathrm{R}_{2}, \mathrm{~A}_{2}\right)$ & $\begin{array}{l}\text { Uma colisão entre moléculas } \\
\text { será efetiva se houver geometria } \\
\text { favorável e energia suficiente para } \\
\text { formar o intermediário (complexo } \\
\text { ativado), que resultará na reação. }\end{array}$ \\
\hline Imutabilidade das bolas de sinuca ${ }^{*}$ & $\stackrel{\mathrm{A}_{3}\left(\mathrm{E}_{1}\right)}{\chi}$ & Mutabilidade das moléculas \\
\hline $\begin{array}{l}\text { Uma colisão efetiva entre duas } \\
\text { bolas de sinuca não as transforma } \\
(*)\end{array}$ & $\underset{\gamma}{\mathrm{R}_{8}\left(\mathrm{R}_{7}, \mathrm{~A}_{3}\right)}$ & $\begin{array}{l}\text { Uma colisão efetiva entre } \\
\text { duas moléculas provoca sua } \\
\text { transformação em novas moléculas }\end{array}$ \\
\hline
\end{tabular}

(*) Assim como no caso da relação $\mathrm{R}_{1}$ mencionada no Quadro 3, bem como da relação $\mathrm{R}_{3}$ mencionada no Quadro 4, nem o atributo $A_{3}$ e nem a relação $R_{8}$ foram enunciados pelo professor nas enunciações que compuseram seu discurso sobre o DB. Mantivemos em todos esses casos a estratégia de explicitar o que pode ser inferido mediante uma análise lógica das comparações, ao considerarmos que pequenas omissões na enunciação de similaridades ou de diferenças entre DB e DA não comprometem a consistência estrutural das comparações construídas pelo professor.

Fonte: elaborado pelos autores.

Ao prosseguir com a analogia entre as possíveis situações em um jogo de sinuca e as colisões entre moléculas para ocorrência de uma reação química, o professor introduziu um segundo atributo $\left(\mathrm{A}_{2}\right)$ aos elementos do DB e do DA que são colocados em correspondência - a energia das partículas. A partir daí, ele constrói mais duas correspondências entre relações de ordem superior $\left(\mathrm{R}_{6}\right.$ e $\left.\mathrm{R}_{7}\right)$, a fim de compartilhar a segunda condição para caracterizar uma colisão efetiva. A relação de ordem superior $\mathrm{R}_{8}$, construída a partir do atributo $\mathrm{A}_{3}$ com a relação $\mathrm{R}_{7}$, indica algo não compartilhado entre bolas de sinuca e moléculas: as últimas possuem átomos agrupados em ligações químicas que são rompidas durante uma colisão efetiva; as primeiras são esferas maciças e indivisíveis, tanto antes, quanto após as colisões. Essa limitação da analogia $\mathbf{F}$ não é explicitada pelo professor, embora possamos entender que tenham sido por ele sugeridas quando ele diz que voltando à reação / diferentemente do jogo / o jogo nos ajuda ((a entender as reações químicas)), mas a situação aqui é bem distinta do jogo. A presença do sinal gráfico semelhante à letra $\mathrm{X}$ sobre as setas bidirecionais que indicam as correspondências identificadas com o atributo $\mathrm{A}_{3}$ e com a relação de ordem superior $\mathrm{R}_{8}$ sinaliza essa diferença importante entre os domínios que compõem a analogia $\mathbf{F}$. 


\section{Comparação I}

Ao abordar a temperatura como um fator capaz de alterar a velocidade de uma reação química, e ao apresentar a diferença entre calor e temperatura, o professor introduz o conceito de temperatura por meio de uma comparação.

$\left(\left(120^{\prime} 57^{\prime \prime}\right)\right)[. .$.$] a temperatura / muitos acham que mede o calor / a temperatura não$ mede o calor! / a temperatura mede o estado de agitação do sistema / a temperatura tá relacionada com a energia cinética média / ((COMPARAÇÃO I - 121'11")) / porque as moléculas / mais ou menos / a gente pode pensar estatisticamente / é que nem aluno no dia de prova / (1s) / tem moléculas que são rápidas / (1s) / como tem muitos alunos que tiram notas boas nas provas / mas tem moléculas que são lentas / como tem alunos que tiram notas mais baixas nas provas / (2s) / ou todos alunos terão a mesma nota nas provas? / ((alguns alunos riem baixo)) / as moléculas não têm a mesma velocidade / as moléculas não se movimentam da mesma maneira / (1s) / então / a temperatura / ela está relacionada / com aquilo que nós chamamos de energia cinética média / $\left(\left(121^{\prime} 48^{\prime \prime}\right)\right)[\ldots]$

O Quadro 6 apresenta o mapeamento estrutural da comparação I.

Quadro 6. Mapeamento estrutural da comparação I que trata da distribuição da energia das partículas na teoria das colisões

\begin{tabular}{|c|c|c|}
\hline Domínio Base & Correspondências & Domínio Alvo \\
\hline Alunos & $\longrightarrow$ & Moléculas \\
\hline Nota & $\mathrm{E}_{2}$ & Energia cinética (movimento) \\
\hline $\begin{array}{c}\text { Prova (instrumento de } \\
\text { avaliação) }\end{array}$ & $\mathrm{E}_{3}$ & Sistema reacional \\
\hline $\begin{array}{l}\text { Notas dos alunos em uma } \\
\text { prova }\end{array}$ & $\mathrm{r}_{3}\left(\mathrm{E}_{1}, \mathrm{E}_{1}, \mathrm{E}_{3}\right)$ & $\begin{array}{l}\text { Energia cinética (movimento) das } \\
\text { moléculas em um sistema reacional }\end{array}$ \\
\hline Nota alta/baixa & $\longleftrightarrow \mathrm{A}_{1}\left(\mathrm{E}_{2}\right)$ & Energia cinética alta/baixa \\
\hline $\begin{array}{l}\text { Nem todos os alunos têm a } \\
\text { mesma nota em uma prova }\end{array}$ & 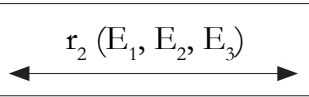 & $\begin{array}{l}\text { Nem todas as moléculas têm a mesma } \\
\text { energia cinética em um sistema reacional }\end{array}$ \\
\hline $\begin{array}{c}\text { Há alunos com bom } \\
\text { desempenho (nota alta) e } \\
\text { alunos com mau desempenho } \\
\text { (nota baixa) }\end{array}$ & $\mathrm{R}_{1}\left(\mathrm{r}_{2}, \mathrm{~A}_{1}\right)$ & $\begin{array}{l}\text { Há moléculas que se movimentam } \\
\text { rapidamente e moléculas que se } \\
\text { movimentam lentamente }\end{array}$ \\
\hline $\begin{array}{c}\text { Entre as notas dos alunos há } \\
\text { uma média }\end{array}$ & $\mathrm{R}_{2}\left(\mathrm{r}_{1}, \mathrm{r}_{2}\right)$ & $\begin{array}{l}\text { Entre os valores de energia cinética das } \\
\text { moléculas há uma média }\end{array}$ \\
\hline
\end{tabular}

Fonte: elaborado pelos autores. 
O mapeamento estrutural da comparação I revelou a correspondência entre três elementos constituintes de cada domínio, duas relações de primeira ordem que organizam esses elementos em unidades semânticas plausíveis, um atributo do segundo elemento mapeado e duas relações de ordem superior que "carregam" as informações pretendidas pelo enunciador. Podemos dizer que essa comparação construída é estruturalmente consistente, pois: (1) cada elemento, atributo e relação enunciados no domínio base estão colocados em correspondência a um elemento, atributo e relação no domínio alvo; (2) as relações mapeadas asseguram a conectividade em paralelo dos elementos correspondentes. Além disso, podemos dizer que essa comparação atende à restrição da sistematicidade na medida em que as duas relações de ordem superior mapeadas $\left(\mathrm{R}_{1}\right.$ e $\left.\mathrm{R}_{2}\right)$ conectam a segunda relação de primeira ordem $\left(\mathrm{r}_{2}\right)$ ao único atributo relevante que foi mapeado e à relação $r_{1}$, respectivamente. Por último, o mapeamento estrutural dessa comparação mostra claramente que o seu foco é essencialmente relacional, o que nos permite classificá-la como uma analogia.

\section{Comparação $\mathbf{M}$}

A comparação $\mathbf{M}$ foi construída pelo professor enquanto ele utilizava o quadro para desenhar o gráfico reproduzido na Figura 1.

$\left(\left(130^{\prime} 07^{\prime \prime}\right)\right)[$ [...] pra vocês entenderem / o que tá acontecendo / eu preciso mostrar um gráfico um pouquinho diferente / o gráfico aqui / é relacionar da seguinte maneira / é um gráfico onde eu tenho / o valor da energia cinética / vamos pensar assim / pode ser entalpia / e aqui / o número de partículas que têm essa energia / (5s) / quando eu pego / um material que está a uma certa temperatura / o gráfico / mais ou menos / tem essa característica aqui oh / (8s) ((o professor desenha no quadro a curva de uma distribuição normal mostrada na figura 2 apresentada a seguir)) / vejam / essa curva que tem a forma de sino / (1s) / né / parece um sino ((130’58”)) / (2s) / é uma curva que a gente chama Gauss ((curva gaussiana)) / Gauss foi quem estudou muito essa distribuição / (1s) / ((COMPARAÇÃO M - 131'04”)) / isso acontece nas provas também / quando vocês fazem provas / vocês vão ter alunos que tiraram notas menores / tem alunos que tiraram notas maiores / mas a maioria dos alunos estão na média / se a gente for ver a média da energia aqui ob / essa aqui seria a energia cinética média / é aonde eu tenho a maioria das moléculas (1s) / o grande número de moléculas está próximo da média / um pouquinho antes / um pouquinho depois / poucas moléculas estão com notas mais baixas / poucas estão com notas mais... altas / mas a maioria tá muito próxima / (3s) / só / que pra reagir / não é a energia cinética média / o quê que é / qual é a energia que é necessária pra reagir? (2s) / qual o nome que nós damos à energia necessária pra reagir? ((alguns alunos responderam energia de ativação)) / energia de ativacão / então quando a gente olha a energia de ativação / vamos imaginar que nesse caso / a energia de ativacão seja essa aqui ob / (1s) / significa / que só essas moléculas que estão pra cá / podem reagir / por que que essas moléculas podem reagir? / (3s) / porque essas moléculas têm energia igual / ou superior à energia de / ativacão / (3s) / tá claro isso? / de todas essas moléculas / só essas podem reagir / imagine o 
Mapeamento estrutural de analogias enunciadas em uma aula ...

seguinte / imagine a seguinte situação / nós fizemos uma prova / aqui na sala / (2s) / mas os alunos não tiveram um bom resultado / (1s) / a média da turma é essa aqui ((o professor faz um gesto dêitico sobre um ponto do gráfico desenhado no quadro)) / mas a média / que é considerada pra aprovação / é essa daqui ((novo gesto dêitico)) / então só esses alunos daqui ((idem)) / que estão com nota igual ou superior à média / os sessenta porcento / (1s) / tá claro? / mas a média da turma / ficou bem abaixo / da média / que é a média de aprovação / (3s) / bom / vamos imaginar agora que en aumentei a temperatura / vamos imaginar então uma nova prova que os alunos fizeram e foram melhor / (1s) ((o professor desenha uma segunda gaussiana deslocada para direita em relação

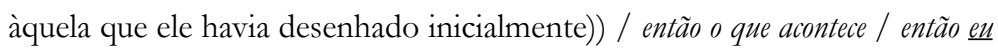
tenho aqui uma temperatura 1 ((novo gesto dêitico sobre um ponto do gráfico)) / e estou imaginando uma temperatura 1 / menor que uma temperatura 2 / então agora en vou pegar essa mesma curva / essa mesma distribuicão / pra uma temperatura maior $\angle$ quando eu tenho uma temperatura maior / eu vou pôr em vermelho ((o professor faz uma intervenção sobre o gráfico desenhado no quadro)) / (3s) / eu vou ter essa situação aqui ob ((novo gesto dêitico)) / (5s) / olha o que acontece / eu ainda tenho alunos que tiram nota baixa / mas é bem menor do que antes / mas a média da turma / a média da turma / é essa aqui oh ((novo gesto dêitico)) / essa é a energia cinética média / na temperatura 2 / essa aqui é na temperatura 1 ((novo gesto dêitico)) / aqui eu tenho a temperatura 2 / (5s) / só que a média da aprovação muda de uma prova pra outra? / a energia de ativacão de una reacão / é fixa / a energia de ativacão ainda continua sendo essa / então agora nessa nova temperatura / quais moléculas é que podem reagir? / (1s) / ora / são as moléculas que têm energia igual / ou superior à energia de ativacão / que não muda / isso aqui é fixo / não muda com a temperatura / então todas essas moléculas aqui / toda essa região que en vou marcar aqui de verde / tem as moléculas que podem reagir / (3s) ((nova intervenção sobre o gráfico)) / então quando eu mudo a temperatura / eu não só aumento a velocidade / tem um fator a mais / o quê que aumentou? / aumentou muito o número de moléculas / que têm energia cinética igual ou superior à energia de... ativacão / e se elas têm energia cinética igual ou maior que a energia de ativacão / elas podem... / ((alguns alunos responderam algo que não pudemos escutar)) / e irão reagir / por isso / a velocidade que en vou ter aqui na temperatura T2 ((novo gesto dêitico)) L vai ser muito maior / que a velocidade que en tinha na temperatura... $\underline{T 1}$ ((novo gesto dêitico)) / vocês estão entendendo o fenômeno? ((135'37")) [...] 
Figura 1. Reprodução da aparência final dos gráficos construídos pelo professor

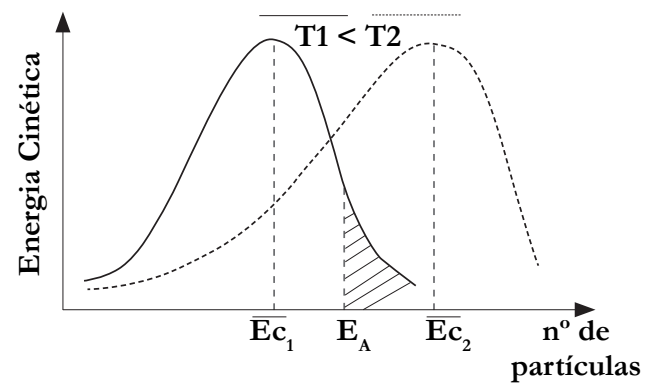

Fonte: elaborada pelos autores a partir das imagens capturadas das aulas no registro em vídeo.

O Quadro 7 apresenta o mapeamento estrutural da comparação $\mathbf{M}$ feito a partir das marcações em negrito e itálico mostradas na transcrição do episódio.

Quadro 7. Mapeamento estrutural da comparação $\mathbf{M}$ que trata do efeito da temperatura na distribuição da energia das partículas na teoria das colisões

\begin{tabular}{|c|c|c|}
\hline Domínio Base & Correspondências & Domínio Alvo \\
\hline Alunos & $\mathrm{E}_{1}$ & Moléculas \\
\hline Nota & $\mathrm{E}_{2}$ & Energia cinética \\
\hline Prova (instrumento de avaliação) & $\longrightarrow \quad \mathrm{E}_{3}$ & Sistema reacional \\
\hline Notas dos alunos em uma prova & $\stackrel{\mathrm{r}_{1}\left(\mathrm{E}_{2}, \mathrm{E}_{1}, \mathrm{E}_{3}\right)}{\longrightarrow}$ & $\begin{array}{c}\text { Energia cinética }\left(\mathrm{E}_{c}\right) \text { das moléculas em um } \\
\text { sistema reacional }\end{array}$ \\
\hline Nota alta / baixa & $\longrightarrow \mathrm{A}_{1}\left(\mathrm{E}_{2}\right)$ & Energia cinética alta / baixa \\
\hline $\begin{array}{l}\text { Nem todos os alunos têm a mesma nota em } \\
\text { uma prova }\end{array}$ & $\underset{\mathrm{r}_{2}\left(\mathrm{E}_{1}, \mathrm{E}_{2}, \mathrm{E}_{3}\right)}{\longrightarrow}$ & $\begin{array}{l}\text { Nem todas as moléculas têm a mesma } \\
\text { energia cinética em um sistema reacional }\end{array}$ \\
\hline $\begin{array}{l}\text { Há alunos com bom desempenho (nota alta) } \\
\text { e alunos com mau desempenho (nota baixa) }\end{array}$ & $\mathrm{R}_{1}\left(\mathrm{r}_{2}, \mathrm{~A}_{1}\right)$ & $\begin{array}{c}\text { Há moléculas que se movimentam } \\
\text { rapidamente e moléculas que se movimentam } \\
\text { lentamente }\end{array}$ \\
\hline Entre as notas dos alunos bá uma média & $\mathrm{R}_{2}\left(\mathrm{r}_{1}, \mathrm{r}_{2}\right)$ & $\begin{array}{l}\text { Entre os valores de energia cinética das } \\
\text { moléculas há uma média }\end{array}$ \\
\hline $\begin{array}{l}\text { Distribuição das notas dos alunos em } \\
\text { torno da média }\end{array}$ & $\mathrm{R}_{2}^{\prime}\left(\mathrm{r}_{1}, \mathrm{r}_{2}\right)$ & $\begin{array}{c}\text { Distribuição da Ec das moléculas em } \\
\text { torno da média }\end{array}$ \\
\hline $\begin{array}{l}\text { Nota mínima para aprovação dos } \\
\text { alunos (“média para aprovação”) }\end{array}$ & $\mathrm{A}_{2}\left(\mathrm{E}_{3}\right)$ & $\begin{array}{c}\text { Ec mínima para ocorrência da reação } \\
\text { química (energia de ativação) }\end{array}$ \\
\hline $\begin{array}{l}\text { Somente alunos com nota igual ou } \\
\text { maior que a média para aprovação } \\
\text { podem ser aprovados }\end{array}$ & $\mathrm{R}_{3}\left(\mathrm{r}_{1}, \mathrm{~A}_{2}\right)$ & $\begin{array}{l}\text { Somente moléculas com energia } \\
\text { cinética igual ou maior que a energia } \\
\text { de ativação podem reagir }\end{array}$ \\
\hline
\end{tabular}


Quadro 7. continuação

\begin{tabular}{|c|c|c|}
\hline Domínio Base & Correspondências & Domínio Alvo \\
\hline $\begin{array}{c}\text { Primeira aplicação de uma prova para } \\
\text { avaliação dos alunos }\end{array}$ & $\underset{\mathrm{E}_{4}}{\longrightarrow}$ & $\begin{array}{l}\text { Primeira condição de temperatura } \\
\text { para ocorrência da reação química }\end{array}$ \\
\hline $\begin{array}{l}\text { Nota média dos alunos na primeira } \\
\text { prova aplicada }\end{array}$ & $\mathrm{R}_{4}\left(\mathrm{R}_{2}, \mathrm{E}_{4}\right)$ & $\begin{array}{c}\text { Ec média das moléculas na } \\
\text { primeira condição de temperatura } \\
\text { (temperatura mais baixa) }\end{array}$ \\
\hline $\begin{array}{l}\text { A nota média dos alunos, na primeira } \\
\text { prova, foi inferior à nota mínima para } \\
\text { aprovação }\end{array}$ & $\mathrm{R}_{5}\left(\mathrm{R}_{4}, \mathrm{~A}_{2}\right)$ & $\begin{array}{l}\text { A Ec média das moléculas, na } \\
\text { primeira condição de temperatura, } \\
\text { foi inferior à energia de ativação da } \\
\text { reação química }\end{array}$ \\
\hline $\begin{array}{l}\text { Na primeira prova houve uma } \\
\text { pequena quantidade de alunos com } \\
\text { nota igual ou superior à nota mínima } \\
\text { para aprovação }\end{array}$ & $\stackrel{\mathrm{R}_{6}\left(\mathrm{R}_{1}, \mathrm{E}_{4}, \mathrm{~A}_{2}\right)}{\longrightarrow}$ & $\begin{array}{l}\text { Na primeira condição de temperatura } \\
\text { houve uma pequena quantidade de } \\
\text { moléculas com Ec igual ou superior à } \\
\text { Ec de ativação }\end{array}$ \\
\hline $\begin{array}{c}\text { Aplicação de outra prova como uma } \\
\text { nova oportunidade para a aprovação } \\
\text { dos alunos }\end{array}$ & $\mathrm{E}_{5}$ & $\begin{array}{l}\text { Aumento da temperatura do } \\
\text { sistema como nova condição para a } \\
\text { ocorrência de uma reação química }\end{array}$ \\
\hline $\begin{array}{c}\text { Redução na quantidade de alunos } \\
\text { com notas inferiores à nota mínima, } \\
\text { na segunda prova aplicada }\end{array}$ & $\stackrel{\mathrm{R}_{7}\left(\mathrm{R}_{1}, \mathrm{R}_{2}^{\prime}, \mathrm{A}_{2}, \mathrm{E}_{5}\right)}{\longrightarrow}$ & $\begin{array}{l}\text { Redução na quantidade de moléculas } \\
\text { com energia inferior à energia de } \\
\text { ativação, na temperatura mais elevada }\end{array}$ \\
\hline $\begin{array}{l}\text { Aumento da nota média dos alunos } \\
\text { na segunda prova }\end{array}$ & $\mathrm{R}_{8}\left(\mathrm{R}_{2}, \mathrm{E}_{5}\right)$ & $\begin{array}{c}\text { Aumento da energia cinética média } \\
\text { das moléculas, na temperatura mais } \\
\text { elevada }\end{array}$ \\
\hline $\begin{array}{l}\text { Conservação do valor da nota } \\
\text { mínima que serve de critério para a } \\
\text { aprovação dos alunos }\end{array}$ & $\mathrm{r}_{3}\left(\mathrm{~A}_{2}, \mathrm{E}_{5}\right)$ & $\begin{array}{c}\text { Conservação do valor da energia de } \\
\text { ativação para a ocorrência da reação } \\
\text { química }\end{array}$ \\
\hline $\begin{array}{c}\text { Aumento da quantidade de alunos } \\
\text { com nota igual ou superior à nota } \\
\text { mínima para aprovação } \\
{ }^{(*)}\end{array}$ & $\mathrm{R}_{9}\left(\mathrm{R}_{8}, \mathrm{R}_{7,} \mathrm{r}_{3}\right)$ & $\begin{array}{c}\text { Aumento da quantidade de moléculas } \\
\text { com energia cinética igual ou superior } \\
\text { à energia de ativação }\end{array}$ \\
\hline
\end{tabular}

(*) No DB, a relação $\mathrm{R}_{9}$ não foi enunciada pelo professor, mas sua presença na comparação $\mathbf{M}$ pode ser inferida. Trata-se do mesmo caso observado na relação $R_{1}$ mencionada no quadro 3 , na relação $R_{3}$ mencionada no quadro 4 , bem como no atributo $A_{3}$ e na relação $R_{8}$ mencionados no quadro 5 .

Fonte: elaborado pelos autores.

O mapeamento estrutural elaborado para a comparação $\mathbf{M}$ nos permite afirmar que o professor estendeu a ideia inicial da comparação $\mathbf{I}$ ao enunciar novamente as relações $r_{1}, r_{2}$ e $\mathrm{R}_{1}$ que constituíram essa comparação. Com a retomada dessas relações, o professor pôde reconceber a relação de ordem superior $\mathrm{R}_{2}$, que deu origem à relação $\mathrm{R}_{2}$ reproduzida no Quadro 7. Além delas, na comparação $\mathbf{M}$, o professor elaborou mais sete correspondências entre relações de ordem superior $\left(\mathrm{R}_{3}\right.$ a $\left.\mathrm{R}_{9}\right)$. Com o auxílio do mapeamento estrutural concluímos que a comparação $\mathbf{M}$ é uma analogia, uma vez que há poucas correspondências entre atributos dos dois domínios e há um predomínio de relações de ordem superior. 
Por fim, é interessante destacar que na construção da analogia $\mathbf{M}$ ocorre uma troca entre as palavras nota e energia cinética, quando o professor fala em notas mais baixas ou mais altas das moléculas. No entanto, a consistência estrutural da comparação é tão alta que essa troca não parece ter interferido na analogia, sendo possível, inclusive que não tenha sido percebida pelo professor ou pelos estudantes.

\section{Considerações finais}

A análise dos registros produzidos na sala de aula investigada nos permitiu reconhecer diferenças entre a diversidade de comparações enunciadas por um professor de Química experiente, bem como analisar a complexidade das relações em correspondência estabelecidas no interior das analogias. Desse modo pudemos responder à questão: que características nos permitem identificar uma comparação estabelecida por um professor como sendo uma analogia?

A teoria do mapeamento estrutural das comparações nos forneceu uma ferramenta de análise útil para alinhar os elementos e os atributos em correspondência e, principalmente, para identificar as relações estabelecidas e inferir seu grau de complexidade. Além disso, o mapeamento estrutural das comparações evidenciou a maneira como analogias construídas em momentos distintos da aula foram retomadas para que o professor pudesse apresentar conceitos e modelos de maior sofisticação, a partir do resgate de conhecimentos prévios dos alunos. Nesse aspecto, o mapeamento estrutural nos permitiu responder à segunda questão: que articulação é estabelecida entre comparações distintas que tratam de um mesmo tema, conceito ou modelo cientifico?

Com o auxílio do mapeamento, mostramos que relações de menor complexidade enunciadas em uma comparação foram ampliadas para a construção de relações de ordem superior em uma comparação posterior. Isso ocorreu na articulação entre a analogia $\mathbf{I}$ e a analogia $\mathbf{M}$. $\mathrm{Na}$ primeira dessas analogias, as relações $\mathrm{R}_{1}$ e $\mathrm{R}_{2}$ serviram para o professor colocar as diferentes energias cinéticas exibidas pelas moléculas de um material em correspondência com as diferentes notas de alunos obtidas em uma prova. Durante a comparação $\mathbf{M}$, essas relações foram a base para a construção das outras relações mais sofisticadas e complexas que permitiram ao professor explicar como o aumento da temperatura eleva a quantidade de moléculas com energia cinética igual ou superior à energia de ativação necessária à ocorrência de uma reação química.

A respeito do papel das analogias na Educação em Ciências, consideramos que o nosso trabalho oferece uma importante contribuição relacionada ao modo como as analogias devem ser compreendidas e analisadas. A teoria que fundamentou o trabalho nos permitiu desenvolver um procedimento de análise sistemático de analogias enunciadas em salas de aula de Ciências, de modo a compreender a grande complexidade das relações construídas e colocadas em correspondência no interior desse tipo de comparação.

\section{Agradecimentos}

Agradecemos o apoio da Fundação de Amparo à Pesquisa do Estado de Minas Gerais (FAPEMIG), e do Grupo de Estudos em Modelos, Metáforas e Analogias na Tecnologia, na Educação e na Ciência (GEMATEC) do CEFET-MG. 
Mapeamento estrutural de analogias enunciadas em uma aula ...

\section{Referências}

BOZELLI, F. C.; NARDI, R. Interações discursivas e o uso de analogias no ensino de física. Investigações em Ensino de Ciências, Porto Alegre, v. 17, n. 1, p. 81-107, 2012. Disponível em: < http://www.if.ufrgs.br/ienci/artigos/Artigo_ID280/v17_n1_a2012.pdf> Acesso em: 15 fev. 2014.

O uso de analogias no ensino de física em nível universitário: interpretaçoes sobre os discursos do professor e dos alunos. Revista Brasileira de Pesquisa em Educação em Ciências, Belo Horizonte, v. 6, n. 3, p. 1-17, 2006. Disponível em: <https://seer.ufmg.br/ index.php/rbpec/article/view/2245/1644> . Acesso em: 12 jan. 2017.

BUTY, C.; MORTIMER, E. F. Dialogic/authoritative discourse and modelling in a high school teaching sequence on optics. International Journal of Science

Education, Abingdon, v. 30, n. 12, p. 1635-1660, 2008. Disponível em: <https://doi. org/10.1080/09500690701466280> . Acesso em: 12 jan. 2017.

DAGHER, Z. Analysis of analogies used by science teachers. Journal of Research in Science Teaching, Hoboken, v. 32, n. 3, p. 259-270, 1995. Disponível em: <https://doi. org/10.1002/tea.3660320306>. Acesso em: 12 jan. 2017.

FERRAZ, D. F.; TERRAZZAN, E. A. O uso de analogias como recurso didático por professores de biologia no ensino médio. Revista Brasileira de Pesquisa em Educação em Ciências, Belo Horizonte, v. 1, n. 3, p. 2001. Disponível em: < https://seer.ufmg.br/ index.php/rbpec/article/view/2367/1767>. Acesso em: 12 jan. 2017.

. O uso espontâneo de analogias por professores de biologia: observações da prática pedagógica. Ensaio: pesquisa em educação em ciências, Belo Horizonte, v. 4, n. 2, p. 1-15, 2002. Disponível em: <http://www.redalyc.org/articulo.oa?id=129517975003>. Acesso em: 10 mar. 2013.

. Uso espontâneo de analogias por professores de biologia e o uso sistematizado de analogias: que relação? Ciência \& Educação, Bauru, v. 9, n. 2, p. 213-227, 2003. Disponível em: <https://doi.org/10.1590/S1516-73132003000200005>. Acesso em: 16 set. 2012.

GENTNER, D. Structure-mapping: a theoretical framework for analogy. Cognitive Science, Hoboken, v. 7, n. 2, p. 155-170, 1983. Disponível em: <https://doi.org/10.1016/ S0364-0213(83)80009-3>. Acesso em: 9 ago. 2013.

GENTNER, D.; MARKMAN, A. B. Structure mapping in analogy and similarity. American Psychologist, Washington, v. 52, n. 1, p. 45-56, 1997. Disponível em: <http://groups.psych. northwestern.edu/gentner/papers/GentnerMarkman97.pdf >. Acesso em: 5 out. 2013.

HARRISON, A. G.; TREAGUST, D. F. Science analogies. The Science Teacher, Arlington, n. 61, n. 4, p. 40-43, 1994.

KRESS, G. et al. Multimodal teaching and learning: the rhetorics of the science classroom. London: Continuuem, 2001. 
Ferry, A. S.; Figueirêdo e Paula, H.

MOZZER, N. B.; JUSTI, R. A elaboração de analogias como um processo que favorece a expressão de concepções de professores de química. Educación Química, México, v. 24, suppl. 1, p. 163-173, 2013. Disponível em: <https://doi.org/10.1016/S0187893X(13)72510-2>. Acesso em: 6 fev. 2015.

. "Nem tudo que reluz é ouro": uma discussão sobre analogias e outras similaridades e recursos utilizados no ensino de ciências. Revista Brasileira de Pesquisa em Educação em Ciências, Belo Horizonte, v. 15, n. 1, p. 123-147, 2015. Disponível em: <https://seer. ufmg.br/index.php/rbpec/article/viewFile/2509/1909>. Acesso em: 10 ago. 2015.

THIELE, R.; TREAGUST, D. An interpretative examination of high school chemistry teachers analogical explanations. Journal of Research in Science Teaching, Hoboken, v. 31, n. 3, p. 227-242, 1994. Disponível em: <https://doi.org/10.1002/tea.3660310304>. Acesso em: 10 jan. 2017.

TREAGUST, D. F. et al. Science teachers' use of analogies: observations from classroom practice. International Journal of Science Education, Abingdon, v. 14, n. 4, p. 413-422, 1992. Disponível em: <https://doi.org/10.1080/0950069920140404>. Acesso em: 10 jan. 2017.

Artigo recebido em 17/11/2015. Aceito em 04/06/2016.

Endereço para contato: Rua Conceição Aparecida Augsten, 280, ap 502,

Bairro Castelo, CEP 30840-400, Belo Horizonte, MG, Brasil. 